\title{
Mechanism of Bone Mineralization
}

\author{
Monzur Murshed ${ }^{1,2,3}$ \\ ${ }^{1}$ Faculty of Dentistry, McGill University, Montreal, Quebec H3A 1G1, Canada \\ ${ }^{2}$ Division of Experimental Medicine, Department of Medicine, McGill University, Montreal, Quebec \\ H4A 3J1, Canada \\ ${ }^{3}$ Shriners Hospital for Children, Montreal, Quebec H4A 0A9, Canada \\ Correspondence: monzur.murshed@mcgill.ca
}

Mineralized "hard" tissues of the skeleton possess unique biomechanical properties to support the body weight and movement and act as a source of essential minerals required for critical body functions. For a long time, extracellular matrix (ECM) mineralization in the vertebrate skeleton was considered as a passive process. However, the explosion of genetic studies during the past decades has established that this process is essentially controlled by multiple genetic pathways. These pathways regulate the homeostasis of ionic calcium and inorganic phosphate-two mineral components required for bone mineral formation, the synthesis of mineral scaffolding ECM, and the maintainence of the levels of the inhibitory organic and inorganic molecules controlling the process of mineral crystal formation and its growth. More recently, intracellular enzyme regulators of skeletal tissue mineralization have been identified. The current review will discuss the key determinants of ECM mineralization in bone and propose a unified model explaining this process.

$\mathrm{T}^{\mathrm{h}}$ he mineralized extracellular matrix (ECM) is anique feature of the vertebrate skeletodental system. The massive load-bearing capacity of the mineralized skeleton permitted the evolutionary emergence of large vertebrates, such as blue whales, which can weigh up to 180 tons. However, the functions of the mineralized tissues are not limited to support the body mass, protect the internal soft organs, or to facilitate locomotion and mastication only; they also serve as a readily accessible reservoir for essential minerals that are indispensable for many physiologic activities. The current review will focus on the mechanism of calcium phosphate biomineralization in the vertebrate skeleton.
The origin of biomineralization has been traced back to the late Precambrian period after tectonic activities caused a marked increase of soluble minerals in the seawater (Wagner and Aspenberg 2011). It is commonly believed that marine organisms first developed primitive exoskeletons made up of calcium carbonate and/or calcium phosphate minerals (Knoll 2003; Wagner and Aspenberg 2011). As part of the process of evolutionary adaptations, the skeletal tissues were internalized, which paved the way for the emergence of organisms with larger body sizes. Whereas it is not clear what prompted some primitive organisms to deposit calcium phosphate instead of calcium carbonate minerals in

Editors: Gerard Karsenty and David T. Scadden

Additional Perspectives on Bone: A Regulator of Physiology available at www.perspectivesinmedicine.org

Copyright (C) 2018 Cold Spring Harbor Laboratory Press; all rights reserved

Advanced Online Article. Cite this article as Cold Spring Harb Perspect Med doi: 10.1101/cshperspect.a031229 
M. Murshed

their skeletal tissues, it is conceivable that the deposited calcium phosphate minerals provided certain physiological advantages. Indeed it has been suggested that the presence of calcium phosphate minerals makes the skeleton more stable under acidic conditions (Wagner and Aspenberg 2011). Vertebrate organisms rely on ATP generation via anaerobic glycolysis for sudden rapid movements during "fight-or-flight" situations. The activation of this pathway results in an acidic tissue environment, which would have destabilized a skeleton made up of calcium carbonate more readily.

\section{MINERAL COMPOSITION OF BONE}

In 1771 , Scheele first reported the presence of calcium phosphate minerals in bone (Scheele 1931). Later, bone mineral was described as a form of hydroxyapatite $\left[(\mathrm{Ca})_{10}\left(\mathrm{PO}_{4}\right)_{6}(\mathrm{OH})_{2}\right]$ comparable to geological apatite (a group of phosphate minerals) by both chemical composition and X-ray diffraction pattern analyses (see Eliaz and Metoki 2017 for a comprehensive review on the historical perspective). However, subsequent studies demonstrated that minerals in bone do not have a uniform composition (Rey et al. 1995; Pasteris et al. 2004). Although there are still some disagreements about the initial phase of the deposited mineral and its time-dependent transition to apatite, it is now accepted that the matured bone mineral is a substituted crystalline phase of calcium phosphate, referred to as carbonated hydroxyapatite (Mahamid et al. 2008). High-resolution transmission electron microscopy (TEM), 3D stereoscopic TEM, and atomic force microscopy on organic matrix-free bone samples provided accurate measurements of bone crystals. These studies have firmly established that bone crystals are nanosized, long, and very thin platelets (Rey et al. 2009).

The source of the dispute regarding the early mineral phase in bone appears to be a simple in vitro experiment performed in the mid-sixties in the laboratory of Dr. Posner (Boskey 1997). The mixing of concentrated solutions of calcium chloride and sodium acid phosphate resulted in the precipitation of calcium phosphate salts, which showed a broad and diffused pattern by
$\mathrm{X}$-ray diffraction analysis. This pattern suggested that the precipitated mineral is amorphous calcium phosphate (ACP), not apatite. Interestingly, when X-ray diffraction analyses were performed on the same samples 2 days later, the precipitates were found to be a poorly formed crystalline apatite (Boskey 1997). This initial finding of mineral phase transition in vitro prompted follow-up experiments using mineralized tissue samples and, subsequently, the presence of ACP in the embryonic chick bones was reported by the same group (Eanes et al. 1965). However, the controversy on whether bone contains ACP continued as later studies concluded that the embryonic bones do not contain ACP (Bonar et al. 1983; Grynpas et al. 1984). Since then, more sophisticated analyses of bone minerals using Raman spectra, Fouriertransform infrared spectroscopy (FTIR), and synchrotron-generated X-ray diffraction techniques have been performed; however, a consensus on the issue is still elusive (Rey et al. 2009).

The presence of amorphous mineral phase has been reported in some invertebrates (Becker et al. 1976, 2005). Additionally, ACP has been detected at the sites of ectopic calcification in the vertebrates (Marulanda et al. 2017). In two studies published by Mahamid et al. (2008, 2010), ACP has been identified as a major mineral phase in zebrafish fin bones, suggesting that amorphous to crystalline phase transition occurs in vivo. On the other hand, concerns have been raised about this latter finding on the ground of technical limitations, including possible mineral phase transition during sample collection and processing (Rey et al. 2009).

\section{DETERMINANTS OF SKELETAL TISSUE MINERALIZATION}

In human embryos, although primary ossification centers of endochondral bones (e.g., vertebrae and long bones) appear between 8 and 12 weeks of gestation, the bulk mineralization of skeletal tissues does not occur until the third trimester (Kovacs 2003). The type I collagenrich ECM in the intramembranous bones mineralizes directly, whereas in the endochondral bones, mineralization starts concomitantly at 
two sites: within the core region of the cartilage anlagen and along the bone collar surrounding it (Karsenty and Wagner 2002). In the cartilage, the type $\mathrm{X}$ collagen matrix synthesized by the hypertrophic chondrocytes serves as the mineral scaffold, whereas in the bone collar (and later in the trabecular bones), the primary mineral scaffolding protein is the osteoblast-derived type I collagen (Karsenty and Wagner 2002). A brief discussion on the key determinants regulating skeletal ECM mineralization is presented below.

\section{Systemic Levels of Calcium and Phosphate Ions}

The chemical structure of bone mineral implies that the extracellular levels of ionic calcium $\left(\mathrm{Ca}^{2+}\right)$ and inorganic phosphate $\left(\mathrm{P}_{\mathrm{i}}\right)$ will be two critical determinants for bone mineralization. Indeed, data from patients and animal models of human diseases clearly demonstrates that the reduction of systemic $\mathrm{P}_{\mathrm{i}}$ levels with or without any alteration of the $\mathrm{Ca}^{2+}$ levels lead to osteomalacia with the characteristic increase of unmineralized osteoid volume. The importance of systemic levels of these mineral ions in bone mineralization was demonstrated by impairment of the 1,25 dihydroxy vitamin $\mathrm{D}_{3}$ signaling pathway. For example, mutations in 25 , hydroxy $\mathrm{D}_{3}-1 \alpha$-hydroxylase (required for functional vitamin $\mathrm{D}$ synthesis) or inactivating mutations in vitamin $\mathrm{D}$ receptor, impair the absorption of $\mathrm{Ca}^{2+}$ and $\mathrm{P}_{\mathrm{i}}$ in the gut (Dardenne et al. 2001; Masuyama et al. 2001; Panda et al. 2001). Additionally, these mutations also reduce the mobilization of these ions from the bone by restricting bone resorption (Suda et al. 1992).

Although $\mathrm{Ca}^{2+}$ and $\mathrm{P}_{\mathrm{i}}$ are both integral parts of bone mineral, genetic experiments in mice suggest that circulating $\mathrm{P}_{\mathrm{i}}$ may have a more prominent role in the regulation of bone mineralization. For example, in Hyp mice with a mutation in the Phex gene (a model of human Xlinked hypophosphatemia $[\mathrm{XLH}]$ ), the calcium level is normal, but the systemic $\mathrm{P}_{\mathrm{i}}$ level is reduced to almost half, causing a severe osteomalacia phenotype (Eicher et al. 1976; Costa et al. 1981). The inactivation of PHEX in the Hyp mice or XLH patients leads to an increase of circulating fibroblast growth factor 23 (FGF23) produced by osteoblasts and osteocytes (Xia et al. 2007). Increased FGF23, in turn, down-regulates the expression of sodium phosphate transporters in the kidney tubules preventing $\mathrm{P}_{\mathrm{i}}$ reabsorption and causing hypophosphatemia. As expected, in $A p o E-F g f 23$ transgenic mice in which systemic FGF23 level increases in the absence of any PHEX mutations, a reduction of systemic $\mathrm{P}_{\mathrm{i}}$ level and osteomalacia comparable to that of Hyp mice have been reported (Bai et al. 2004). The similarity of the osteomalacia traits in ApoEFgf23 and Hyp mice suggests that the accompanied hypophosphatemia is the main cause of the phenotype in these two models.

More recently, osteopontin, a protein belonging to the family of small integrin-binding ligand, $N$-linked glycoproteins (SIBLINGs), has been shown as a substrate for PHEX (Barros et al. 2013). It has been proposed that in the absence of PHEX, accumulation of osteopontin in the ECM may contribute to the "hard" tissue mineralization defects seen in the XLH patients and in Hyp mice. Another SIBLING protein, dentin matrix protein 1 (DMP1), has been shown to be an important regulator of circulating FGF23 levels (Martin et al. 2011). As is the case with the inactivating mutations in PHEX, DMP1 deficiency leads to severe osteomalacia.

A severe osteomalacia phenotype is also seen in the calcium sensing receptor (CaSR) knockout mice. The ablation of the Casr gene leads to a marked increase of systemic parathyroid hormone (PTH) levels leading to hypercalcemia accompanied by hypophosphatemia as a result of increased urinary excretion of $\mathrm{P}_{\mathrm{i}}$ (Tu et al. 2003). Interestingly, the observed increase of $\mathrm{Ca}^{2+}$ in the circulation failed to prevent osteomalacia in these mice. On the other hand, an opposite phenotype has been seen in mice lacking glial cell missing 2 (GCM2), a transcription factor required for the development of the parathyroid gland (Gunther et al. 2000). The ablation of Gcm2 impairs the development of the parathyroid gland causing a marked reduction of PTH level in the circulation. A basal PTH level is maintained as the thymus acts as a secondary source for the hormone. As expected, the sur- 
viving $\mathrm{Gcm} 2^{-1-}$ mice show a reduction of serum $\mathrm{Ca}^{2+}$ levels and an increase of serum $\mathrm{P}_{\mathrm{i}}$ levels. However, despite the significant reduction of systemic $\mathrm{Ca}^{2+}$ levels, no osteomalacia was observed in these mice (Gunther et al. 2000).

Currently, a mouse model showing isolated hypocalcemia with a normal serum $\mathrm{P}_{\mathrm{i}}$ level is unavailable. Considering that $\mathrm{Ca}^{2+}$ is an integral component of bone mineral, it is possible that such a model of isolated hypocalcemia, if existed, would have shown impaired bone mineralization. However, phenotypic comparisons of the mouse models with abnormal $\mathrm{Ca}^{2+}$ and/or $\mathrm{P}_{\mathrm{i}}$ homeostasis discussed above suggest that the osteomalacia phenotype in a model of isolated hypocalcemia may not be as severe as seen in isolated hypophosphatemia. Because of the critical role of $\mathrm{Ca}^{2+}$ in many physiologic activities, its serum level is more tightly regulated than that of $\mathrm{P}_{\mathrm{i}}$. Moreover, ubiquitously present inorganic pyrophosphate $\left(\mathrm{PP}_{\mathrm{i}}\right)$, a potent inhibitor of ECM mineralization, is a $\mathrm{P}_{\mathrm{i}}$ derivative (see below) (Terkeltaub 2001). These observations suggest that early organisms depositing calcium phosphate minerals in the skeletal tissues evolved to regulate ECM mineralization by modulating the $\mathrm{P}_{\mathrm{i}}$ levels and its incorporation into the growing mineral crystals.

\section{Collagen Scaffold}

The organic part of the bone ECM is primarily composed of type I collagen. Two genes, Colla 1 and Colla2, encode the $\alpha 1$ and $\alpha 2$ chains of type I collagen, respectively. Two $\alpha 1$ and one $\alpha 2$ chains assemble together to form the collagen triple helix in the extracellular spaces of the bone microenvironment. In a hierarchical fashion, these helices are first arranged axially in a staggered manner as collagen fibrils, which are then bundled together to form the collagen fibers (Shoulders and Raines 2009). In a healthy individual, the mineralization of the unmineralized collagen (osteoid) occurs seamlessly in continuation of the existing mineralized matrix on which the newly synthesized osteoid is deposited by the osteoblasts.

The involvement of collagen in bone mineralization came from the initial electron micros- copy of the mineralizing bones from newborn mice by Sheldon and Robinson (1957). Although earlier studies provided circumstantial evidence that mineral crystals are deposited within the collagen fibrils, this study first demonstrated that there are two sites on the collagen matrix in bone where mineral deposition starts (1) at the intrafibrillar gap spaces, where the carboxy- and amino-terminal ends of two serially arranged collagen triple helices meet, and (2) interfibrillar spaces between the fibrils (Sheldon and Robinson 1957). Since then, numerous studies have confirmed the critical role of collagen matrix as a scaffold for bone mineral deposition. These include the initial studies demonstrating that collagen sponges can be mineralized in vitro, implanted collagen can mineralize in vivo, and demineralized bone collagen can be mineralized under a cell-free condition (Mergenhagen et al. 1960; Bachra and Fischer 1968a,b). More recently, genetic experiments have demonstrated that the reduction of collagen synthesis in bone results in a reduction of mineralized bone mass (Yang et al. 2004).

The exact mechanism by which the collagen lattice facilitates mineral deposition is still unknown. The amino acid side chains exposed at the intrafibrillar gap space and at the interfibrillar space may regulate this process. However, it is possible that the dense packaging of collagen molecules and their hierarchical organization, rather than the primary structure of the protein is the driving force underlying the nucleation of hydroxyapatite. Indeed, one theory attempts to explain the mineralization of bone ECM by the size-exclusion properties of the collagen scaffold (Toroian et al. 2007; Price et al. 2009). According to this theory, the nanoscale gaps present within a collagen fibril and in between the fibrils arranged in a fiber allow the access of $\mathrm{Ca}^{2+}$ and $\mathrm{P}_{\mathrm{i}}$ ions, but not the large proteins, which can inhibit the formation and growth of the nascent hydroxyapatite crystals inside the scaffold.

\section{Mineralization Inhibitors}

Considering that the concentrations of various ions in all the tissues of the body are at equilibrium to that of blood, it is likely that $\mathrm{Ca}^{2+}$ and $\mathrm{P}_{\mathrm{i}}$ 
levels do not differ significantly between the "soft" and skeletal "hard" tissues. This may raise the question-why do some "soft" tissues, such as blood vessels and some cartilaginous tissues, never mineralize despite their high collagen content? The most straightforward answer to this question can be obtained from several human diseases of pathologic "soft" tissue mineralization and their animal models. For example, generalized arterial calcification in infancy (GACI) and progressive ankylosis in humans are both caused by the reduced level of $\mathrm{PP}_{\mathrm{i}}$ in the bone joints (Ho et al. 2000; Albright et al. 2015). $\mathrm{PP}_{\mathrm{i}}$ is a mineralization inhibitor that is known for its potent antimineralization properties for over 50 years (Fleisch and Bisaz 1962). A wide distribution of the $\mathrm{PP}_{\mathrm{i}}$ synthesis and/ or extracellular transport machinery in vertebrate organisms prevents pathologic "soft" tissue mineralization.

$\mathrm{PP}_{\mathrm{i}}$ is composed of two inorganic $\mathrm{P}_{\mathrm{i}}$ groups joined by an ester linkage (Terkeltaub 2001). This inorganic mineralization inhibitor is produced both intracellularly and extracellularly via enzymatic reactions. Intracellularly, $\mathrm{PP}_{\mathrm{i}}$ can be generated as a byproduct of enzymatic activities in numerous metabolic pathways. Intracellular $\mathrm{PP}_{\mathrm{i}}$ is transported to the extracellular space through a transmembrane transporter called ANK (Ho et al. 2000). On the other hand, extracellularly, a direct cleavage of the phosphodiester bond in purine and pyrimidine nucleoside triphosphates (e.g., ATP) by nucleotide pyrophosphatase/phosphodiesterase enzymes can also generate $\mathrm{PP}_{\mathrm{i}}$ (Hessle et al. 2002).

At a threshold concentration, $\mathrm{PP}_{\mathrm{i}}$ prevents the incorporation of $\mathrm{Ca}^{2+}$ and $\mathrm{P}_{\mathrm{i}}$ into nascent apatitic crystals and inhibits their growth (Terkeltaub 2001). Studies on the genetic models have identified the key proteins involved in $\mathrm{PP}_{\mathrm{i}}$-mediated inhibition of pathologic calcification. In a mouse model of human progressive ankylosis with homozygous mutations in the Ank gene (ank/ank), massive mineral deposition is seen in the joints and other soft tissues (Ho et al. 2000). A similar phenotype has been seen in $t$ tw/ttw mice, which carry homozygous mutations in the ectonucleotide phosphodies- terase nucleotide pyrophosphatase I (Enpp1) gene (Koshizuka et al. 2001).

Interestingly, both $A n k$ and Enpp1 genes are highly expressed in bone, more specifically in the osteoblasts (Murshed et al. 2005). Although the presence of a mineralization inhibitor in bone may appear counterintuitive, this quandary can be explained by the presence of a strong alkaline phosphatase (ALPL) activity in bone. The cardinal role of ALPL during skeletal mineralization in humans was demonstrated by many different mutations identified in the $A L P L$ gene in hypophosphatasia patients, causing a wide range of phenotypic severity. Some of these patients show very severe osteomalacia and fetal/perinatal lethality, while others show milder, progressive osteomalacia later in life (Mornet 2000; Taillandier et al. 2000, 2001). The genetic models lacking ALPL activity further confirmed the requirement of this enzyme for bone mineralization (Fedde et al. 1999; Anderson et al. 2004).

ALPL-mediated hydrolysis of $\mathrm{PP}_{\mathrm{i}}$ has two implications-first, it reduces the amount of $\mathrm{PP}_{\mathrm{i}}$ in the bone microenvironment and, second, it increases the amount of mineralization-promoting $\mathrm{P}_{\mathrm{i}}$ ions by liberating them from $\mathrm{PP}_{\mathrm{i}}$. These coupled activities alter the $\mathrm{P}_{\mathrm{i}} / \mathrm{PP}_{\mathrm{i}}$ ratio in the bone ECM in such a way that the formation and growth of the apatite crystal is promoted (Hessle et al. 2002; Murshed et al. 2005). The critical effect of this ratio in regulating ECM mineralization has been demonstrated in ank/ ank;Hyp compound-mutant mice, which show a marked reduction of joint mineralization (Murshed et al. 2005). The low extracellular $\mathrm{P}_{\mathrm{i}} /$ $\mathrm{PP}_{\mathrm{i}}$ ratio in these mice in comparison to the original ank/ank mice prevented the ectopic mineral deposition.

The ALPL "knockout" mice were used to validate the therapeutic effectiveness of a genetically engineered ALPL molecule with the ability to bind to the bone matrix in vivo. These mice showed a remarkable improvement of the bone phenotype, as the hypophosphatasia-associated osteomalacia was prevented (Yadav et al. 2011a). This approach of enzyme-replacement therapy has been successfully used to treat the hypophosphatasia-associated skeletal abnormalities in human clinical trials (Kitaoka et al. 2017). 
M. Murshed

Matrix Gla protein (MGP) and fetuin, two proteins involved in the prevention of "soft" tissue mineralization are also present in the skeletal hard tissues (Jahnen-Dechent et al. 1997). However, considering that fetuin "knockout" mice do not show any overt bone mineralization defects or skeletal anomalies, the current discussion will focus on MGP only. In humans, the homozygous loss-of-function mutations in MGP leads to a rare genetic disorder known as Keutel syndrome (Fryns et al. 1984; Munroe et al. 1999). The patients show abnormal mineralization of their cartilaginous tissues leading to midface hypoplasia, shortening of terminal phalanges, tracheobronchial calcification, and vascular abnormalities, including calcification of the arterial media. MGP-deficient mice recapitulated all of these anomalies albeit with a more severe vascular calcification phenotype (Luo et al. 1997).

MGP, a small mineral-binding protein is highly expressed by chondrocytes and vascular smooth muscle cells (Luo et al. 1995, 1997). Although MGP was initially purified from the bovine bones, its expression is markedly lower in the trabecular bones in comparison to the prehypertrophic zone of the developing growth plate (Price and Williamson 1985; Luo et al. 1995). This expression pattern suggests that MGP present in bone might have originated elsewhere (e.g., in the vascular tissues) and transported to bone via blood. Transgenic overexpression of $M g p$ in the osteoblasts resulted in a moderate level of osteomalacia affecting both intramembranous and endochondral bones (Murshed et al. 2004). This observation highlights the importance of the mechanisms to control the expression of mineralization inhibitors in the mineralizing skeletal tissues.

In agreement with the observation that $M g p$ is weakly expressed in bone in comparison to the cartilaginous tissues, the whole-body ablation of $M g p$ in mice does not overtly affect bone mineralization, but shows skeletal anomalies associated with abnormal cartilage mineralization (Marulanda et al. 2017). The most prominent of these anomalies is midface hypoplasia, which is also seen in the patients with Keutel syndrome. Cephalometric analyses of the microcomputed tomography (CT) images of the head revealed that the phenotype is caused by the impaired growth of the maxillary and palatine bones in comparison to the mandibular bones. Marulanda et al. (2017) reported that the hypoplastic midface was not a result of craniosynostosis as seen in several other mouse models of midface hypoplasia, but a result of ectopic mineralization of the cartilaginous part of the nasal septum, which normally does not mineralize. This abnormal mineralization induced apoptosis of the chondrocytes present in the nasal septum (Marulanda et al. 2017). The loss of the matrix synthesizing active chondrocytes during the early growth phase and the increased rigidity of the ECM upon mineralization might have impaired the growth of the nasal septum and that of the maxillary complex. Interestingly, the deposited minerals in the septal cartilage of the mutant mice show the presence of ACP, suggesting that MGP-mediated inhibition of mineralization occurs during the early phases of mineral precipitation.

\section{THE ROLE OF INTRACELLULAR ENZYMES IN SKELETAL MINERALIZATION}

Whereas most of the published work on the mechanism of cartilage and bone mineralization focuses primarily on the extracellular determinants, newer studies have identified several intracellular enzymes as important regulators of this process. The main strength of these studies is the use of in vivo gene ablation models exhibiting obvious "hard" tissue mineralization defects, which are not caused by the alterations of the known determinants discussed above. The intracellular enzymes, sphingomyelin phosphodiesterase 3 (SMPD3) and phosphatase orphan 1 (PHOSPHO1) reported by these studies are both involved in the metabolism of phospholipids and/or associated metabolites (Aubin et al. 2005; Macrae et al. 2010).

SMPD3 (also known as neutral sphingomyelinase 2) is a cell membrane-bound lipidmetabolizing enzyme expressed in high amounts in the brain, cartilage, and bone. Among various acid, basic, and neutral sphingomyelinases, only SMPD3 deficiency leads to impaired mineralization of the skeletal tissues (Stoffel et al. 2005, 
2007; Macrae et al. 2010; Khavandgar and Murshed 2015). SMPD3 cleaves sphingomyelin present in the cell membrane to generate ceramide, a bioactive lipid molecule, and phosphocholine, an essential nutrient. Emerging data from the analysis of genetically altered mouse models suggest that SMPD3 activity during embryonic development plays a critical role in normal skeletogenesis. This insight originally came from two different mouse models lacking SMPD3. One of these models, fro/fro, carries a chemically induced deletion encompassing part of intron 8 and most of exon 9 of the Smpd3 gene, whereas the other mouse model (Smpd $3^{-/-}$) was generated by the conventional gene-targeting approach (Aubin et al. 2005; Stoffel et al. 2005, 2007).

The fro mutation completely abolishes the enzymatic activity of SMPD3, but does not affect its membrane localization (Khavandgar et al. 2011). A severe mineralization defect affecting both intramembranous and endochondral bones, and an abnormal delay of apoptosis of the hypertrophic chondrocytes during the early stages of skeletal development are the hallmarks of the skeletal phenotypes in fro/fro mice. Recently, Li et al. have demonstrated that SMPD3 activity in both chondrocytes and osteoblasts are required for a normal bone development ( $\mathrm{Li}$ et al. 2016). The poor mineralization of the skeletal tissues in fro/fro mice is seen without any alterations of the homeostasis of $\mathrm{Ca}^{2+}, \mathrm{P}_{\mathrm{i}}$, and $\mathrm{PP}_{\mathrm{i}}$ (Khavandgar et al. 2011). This observation suggests that the loss of SMPD3 function affects ECM mineralization through a novel, yet unknown, mechanism.

As mentioned above, SMPD3 cleaves sphingomyelin to generate many different species of ceramides that regulate a myriad of cell functions. SMPD3 activity also liberates an essential nutrient, phosphocholine. Whereas the role of ceramide is well documented in the regulation of apoptosis (Obeid et al. 1993), it is not yet clear whether both ceramide and phosphocholine or only one of these metabolites is involved in skeletal tissue mineralization. Interestingly, gene knockout experiments reducing ceramide biosynthesis via an alternative pathway without involving SMPD3 activity did not report any ECM mineralization defects (Holland et al. 2007). These findings lead to two conclusions: it is possible that the ceramides generated from these two pathways contribute to different pools with distinct cellular functions; alternatively, it is possible that ceramide does not play a role in the process of bone mineralization. While at present, no experimental data directly suggests the involvement of ceramide in ECM mineralization, the importance of phosphocholine in this process has been convincingly shown by animal experiments (Macrae et al. 2010; Yadav et al. 2011b). Phosphocholine generated from sphingomyelin by SMPD3, or from dietary choline by two isoforms of choline kinases, can be cleaved by $\mathrm{PHOSPHO1,} \mathrm{an} \mathrm{intracellular} \mathrm{enzyme}$ with phosphatase activity. The deficiency of PHOSPHO1 in mice has been shown to cause similar bone mineralization defects as seen in fro/fro mice (Yadav et al. 2011b).

\section{INTRACELLULAR REGULATORS OF ECM MINERALIZATION AND THE "MATRIX VESICLE THEORY"}

Whereas the regulatory roles of two intracellular enzymes, SMPD3 and PHOSPHO1, in ECM mineralization are now well established, the question remains how these intracellular enzymes may regulate a process that occurs outside the cells. A possible mechanism may involve matrix vesicles (MVs), which are nanosized $(20-200 \mathrm{~nm})$ vesicles released by the cells in a mineralizing tissue (Anderson et al. 2004, 2005; Golub 2009; Wu et al. 2002). Since their initial discoveries as chondrocyte-derived vesicular bodies promoting the initiation of mineral nucleation, there have been considerable efforts to explain various types of ECM mineralization, including pathologic mineralization of "soft tissues" using the "matrix vesicle theory" (Anderson 1984). Although there is no general consensus, it has been suggested that MVs provide an isolated microenvironment to facilitate the initial nucleation of apatite mineral. Mineral crystals formed inside the MVs grow progressively in size by the addition of $\mathrm{Ca}^{2+}$ and $\mathrm{P}_{\mathrm{i}}$ ions and eventually rupture the MV membrane to be deposited on the collagen scaffold. 


\section{Murshed}

Wu et al. (2002) showed extensive phospholipid degradation in the mineralizing MVs with a concomitant increase of free fatty acids. This observation suggested the presence of phospholipase activity inside the MVs and demonstrated a link between phospholipid metabolism and the initiation of ECM mineralization. Phospholipase activity generates phosphocholine and phosphoethanolamine, which can be cleaved by PHOSPHO1 releasing free $\mathrm{P}_{\mathrm{i}}$ inside the MVs. The increase of $\mathrm{Pi}$ inside the MVs may alter the $\mathrm{P}_{\mathrm{i}} / \mathrm{PP}_{\mathrm{i}}$ ratio to favor the seeding of early mineral crystals.

Being a membrane-bound enzyme with an intracellular catalytic domain, SMPD3 is expected to be present inside the MVs. The cleavage of sphingomyelin present in the MV membrane by
SMPD3 may generate additional phosphocholine to be cleaved by PHOSPHO1. Although further studies will be needed to establish that SMPD3 and PHOSPHO1 works in a relay in the MVs, such a possibility is supported by the observation that both PHOSPHO1 and SMPD3 are present in the MV preparations (Mebarek et al. 2013). Apart from its role described above, SMPD3 might be involved in the biogenesis of the MVs.

\section{SUMMARY}

Based on the discussion above, a unified model for bone mineralization can be proposed. When present at physiologic concentrations, two mineral ions- $\mathrm{Ca}^{2+}$ and $\mathrm{P}_{\mathrm{i}}$-will promote hydroxy-

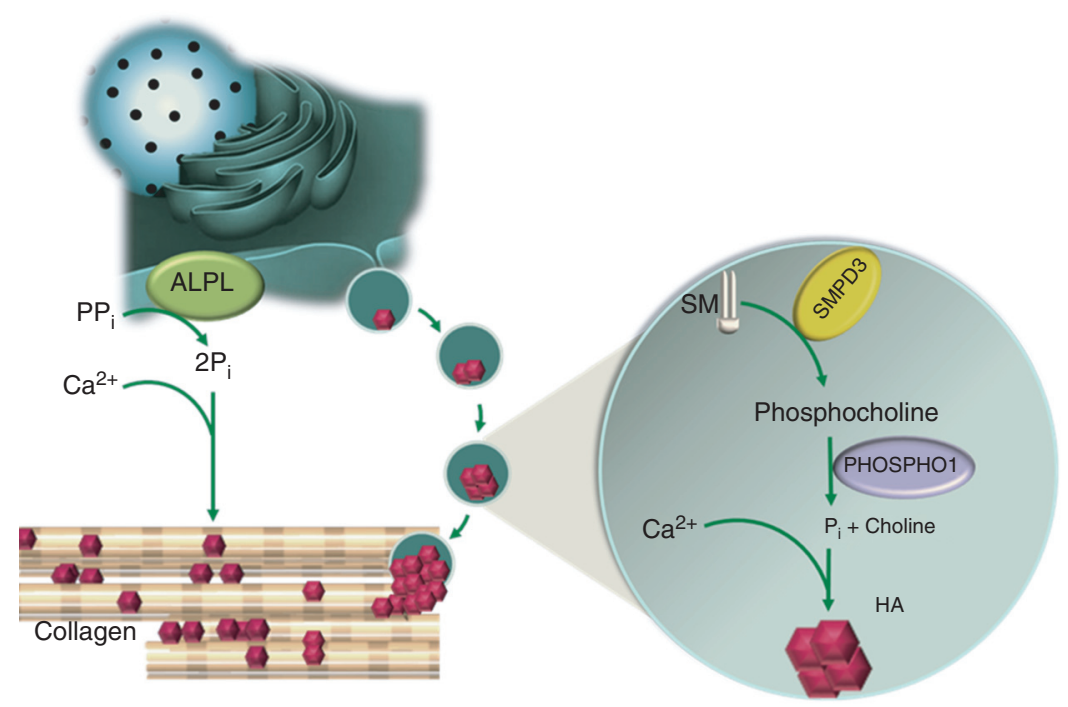

Figure 1. Model of bone mineralization. Serum calcium $\left(\mathrm{Ca}^{2+}\right)$, inorganic phosphate $\left(\mathrm{P}_{\mathrm{i}}\right)$ levels, and a mineral scaffolding collagen-rich extracellular matrix (ECM) are important determinants of bone mineralization. Alkaline phosphatase (ALPL), an ectoenzyme tethered to the osteoblast cell membrane, cleaves inorganic pyrophosphate $\left(\mathrm{PP}_{\mathrm{i}}\right)$, a small, but potent mineralization inhibitor. This facilitates bone ECM mineralization in two ways: first, it reduces the level of a mineralization inhibitor, and second, in the process generates $\mathrm{P}_{\mathrm{i}}$, an activator of ECM mineralization. This coupled ALPL activity alters the $\mathrm{P}_{\mathrm{i}} / \mathrm{PP}_{\mathrm{i}}$ ratio in the bone microenvironment to favor bone mineralization. Compact hierarchical assembly of collagen molecules in the fibrils and fibers results in both intraand interfibrillar nanoscale gaps. These gaps are accessible by $\mathrm{Ca}^{2+}$ and $\mathrm{P}_{\mathrm{i}}$ ions, but not by the large protein inhibitors of ECM mineralization. This may explain why there are mineral deposits both inside and in the gaps in between the collagen fibrils. Matrix vesicle (MV)-mediated mineralization may serve as an auxiliary mechanism for bone mineralization. These nanoscale vesicles carrying the intracellular mineralization-promoting enzymes bud off from the mineralizing cells. Enzymes like SMPD3 and phospholipases present inside the MVs may cleave the phospholipids (e.g., sphingomyelin [SM]) to generate phosphocholine, which in turn can be cleaved by another cytosolic enzyme PHOSPHO1 liberating free $\mathrm{P}_{\mathrm{i}}$. An increase of intravesicular $\mathrm{P}_{\mathrm{i}}$ leads to its precipitation with $\mathrm{Ca}^{2+}$ to form the nascent hydroxyapatite (HA) crystals. 
apatite crystal growth within and between the newly synthesized collagen fibrils in the skeletal ECM. $\mathrm{PP}_{\mathrm{i}}$, a chemical derivative of $\mathrm{P}_{\mathrm{i}}$, can inhibit the mineralization process. The presence of a scaffolding matrix and a defined extracellular ratio of $\mathrm{P}_{\mathrm{i}}$ to $\mathrm{PP}_{\mathrm{i}}$ are two critical determinants of ECM mineralization. ALPL, an ectoenzyme bound to the osteoblast cell membrane, cleaves $\mathrm{PP}_{\mathrm{i}}$ to generate $\mathrm{P}_{\mathrm{i}}$ and alters the local $\mathrm{P}_{\mathrm{i}}$ to $\mathrm{PP}$ ratio to favor mineral precipitation (Fig. 1).

The above model suggests that the specificity of skeletal mineralization can be explained, in part, by the unique coexpression of tissue-nonspecific genes encoding type I collagen and ALPL. Indeed as in vivo proof for this hypothesis, it was demonstrated that when the $\mathrm{PP}_{\mathrm{i}}$ cleaving enzyme, ALPL, was mis-expressed in the dermis and arterial media, tissues rich in fibrillar collagen, it caused rapid ECM mineralization (Murshed et al. 2005). However, it should be noted that this finding does not rule out the existence of auxiliary mechanisms working together to mineralize the skeletal ECM. The possibility of additional mechanism(s) is supported by the fact that both SMPD3- and PHOSPHO1-deficient mice show bone mineralization defects. These enzymes may work in concert to increase the $\mathrm{P}_{\mathrm{i}}$ levels to facilitate the nucleation of minerals inside the MVs (Fig. 1).

\section{REFERENCES}

Albright RA, Stabach P, Cao W, Kavanagh D, Mullen I, Braddock AA, Covo MS, Tehan M, Yang G, Cheng Z, et al. 2015. ENPP1-Fc prevents mortality and vascular calcifications in rodent model of generalized arterial calcification of infancy. Nat Commun 6: 10006.

Anderson HC. 1984. Mineralization by matrix vesicles. Scan Electron Microsc 2: 953-964.

Anderson HC, Sipe JB, Hessle L, Dhanyamraju R, Atti E, Camacho NP, Millán JL, Dhamyamraju R. 2004. Impaired calcification around matrix vesicles of growth plate and bone in alkaline phosphatase-deficient mice. Am J Patho 164: 841-847.

Anderson HC, Garimella R, Tague SE. 2005. The role of matrix vesicles in growth plate development and biomineralization. Front Biosci 10: 822-837.

Aubin I, Adams CP, Opsahl S, Septier D, Bishop CE, Auge N, Salvayre R, Negre-Salvayre A, Goldberg M, Guénet JL, et al. 2005. A deletion in the gene encoding sphingomyelin phosphodiesterase 3 (Smpd3) results in osteogenesis and dentinogenesis imperfecta in the mouse. Nat Genet 37: 803-805.
Bachra BN, Fischer HR. 1968a. Mineral deposition in collagen in vitro. Calcif Tissue Res 2: 343-352.

Bachra BN, Fischer HR. 1968b. Recalcification of decalcified bone collagen in vitro as a model for biologic calcification. Calcif Tissue Res 2: 7.

Bai X, Miao D, Li J, Goltzman D, Karaplis AC. 2004. Transgenic mice overexpressing human fibroblast growth factor 23 (R176Q) delineate a putative role for parathyroid hormone in renal phosphate wasting disorders. Endocrinology 145: 5269-5279.

Barros NM, Hoac B, Neves RL, Addison WN, Assis DM, Murshed M, Carmona AK, McKee MD. 2013. Proteolytic processing of osteopontin by PHEX and accumulation of osteopontin fragments in Hyp mouse bone, the murine model of X-linked hypophosphatemia. J Bone Miner Res 28: 688-699.

Becker GL, Termine JD, Eanes ED. 1976. Comparative studies of intra- and extramitochondrial calcium phosphates from the hepatopancreas of the blue crab (Callinectes sapidus). Calcif Tissue Res 21: 105-113.

Becker A, Ziegler A, Epple M. 2005. The mineral phase in the cuticles of two species of Crustacea consists of magnesium calcite, amorphous calcium carbonate, and amorphous calcium phosphate. Dalton Trans 10: 1814-1820.

Bonar LC, Roufosse AH, Sabine WK, Grynpas MD, Glimcher MJ. 1983. X-ray diffraction studies of the crystallinity of bone mineral in newly synthesized and density fractionated bone. Calcif Tissue Int 35: 202-209.

Boskey AL. 1997. Amorphous calcium phosphate: The contention of bone. J Dent Res 76: 1433-1436.

Costa T, Marie PJ, Scriver CR, Cole DE, Reade TM, Nogrady B, Glorieux FH, Delvin EE. 1981. X-linked hypophosphatemia: Effect of calcitriol on renal handling of phosphate, serum phosphate, and bone mineralization. J Clin Endocrinol Metab 52: 463-472.

Dardenne O, Prud'homme J, Arabian A, Glorieux FH, StArnaud R. 2001. Targeted inactivation of the 25-hydroxyvitamin $\mathrm{D}(3)-1(\alpha)$-hydroxylase gene (CYP27B1) creates an animal model of pseudovitamin D-deficiency rickets. Endocrinology 142: 3135-3141.

Eanes ED, Gillessen IH, Posner AS. 1965. Intermediate states in the precipitation of hydroxyapatite. Nature 208: 365367.

Eicher EM, Southard JL, Scriver CR, Glorieux FH. 1976. Hypophosphatemia: Mouse model for human familial hypophosphatemic (vitamin D-resistant) rickets. Proc Natl Acad Sci 73: 4667-4671.

Eliaz N, Metoki N. 2017. Calcium phosphate bioceramics: A review of their history, structure, properties, coating technologies and biomedical applications. Materials (Basel) 10: E334.

Fedde KN, Blair L, Silverstein J, Coburn SP, Ryan LM, Weinstein RS, Waymire K, Narisawa S, Millán JL, MacGregor GR, et al. 1999. Alkaline phosphatase knock-out mice recapitulate the metabolic and skeletal defects of infantile hypophosphatasia. J Bone Miner Res 14: 2015-2026.

Fleisch H, Bisaz S. 1962. Mechanism of calcification: Inhibitory role of pyrophosphate. Nature 195: 911.

Fryns JP, van Fleteren A, Mattelaer P, van den Berghe H. 1984. Calcification of cartilages, brachytelephalangy and 
M. Murshed

peripheral pulmonary stenosis. Confirmation of the Keutel syndrome. Eur J Pediatr 142: 201-203.

Golub EE. 2009. Role of matrix vesicles in biomineralization. Biochim Biophys Acta 1790: 1592-1598.

Grynpas MD, Bonar LC, Glimcher MJ. 1984. Failure to detect an amorphous calcium-phosphate solid phase in bone mineral: A radial distribution function study. Calcif Tissue Int 36: 291-301.

Gunther T, Chen ZF, Kim J, Priemel M, Rueger JM, Amling M, Moseley JM, Martin TJ, Anderson DJ, Karsenty G. 2000. Genetic ablation of parathyroid glands reveals another source of parathyroid hormone. Nature 406: 199203.

Hessle L, Johnson KA, Anderson HC, Narisawa S, Sali A, Goding JW, Terkeltaub R, Millan JL. 2002. Tissue-nonspecific alkaline phosphatase and plasma cell membrane glycoprotein-1 are central antagonistic regulators of bone mineralization. Proc Natl Acad Sci 99: 9445-9449.

Ho AM, Johnson MD, Kingsley DM. 2000. Role of the mouse ank gene in control of tissue calcification and arthritis. Science 289: 265-270.

Holland WL, Brozinick JT, Wang LP, Hawkins ED, Sargent KM, Liu Y, Narra K, Hoehn KL, Knotts TA, Siesky A, et al. 2007. Inhibition of ceramide synthesis ameliorates glucocorticoid-, saturated-fat-, and obesity-induced insulin resistance. Cell Metab 5: 167-179.

Jahnen-Dechent W, Schinke T, Trindl A, Müller-Esterl W, Sablitzky F, Kaiser S, Blessing M. 1997. Cloning and targeted deletion of the mouse fetuin gene. J Biol Chem 272: 31496-31503.

Karsenty G, Wagner EF. 2002. Reaching a genetic and molecular understanding of skeletal development. Dev Cell 2: 389-406.

Khavandgar Z, Murshed M. 2015. Sphingolipid metabolism and its role in the skeletal tissues. Cell Mol Life Sci 72: 959-969.

Khavandgar Z, Poirier C, Clarke CJ, Li J, Wang N, McKee MD, Hannun YA, Murshed M. 2011. A cell-autonomous requirement for neutral sphingomyelinase 2 in bone mineralization. J Cell Biol 194: 277-289.

Kitaoka T, Tajima T, Nagasaki K, Kikuchi T, Yamamoto K, Michigami T, Okada S, Fujiwara I, Kokaji M, Mochizuki H, et al. 2017. Safety and efficacy of treatment with asfotase alfa in patients with hypophosphatasia: Results from a Japanese clinical trial. Clin Endocrinol (Oxf) 87: 10-19.

Knoll AH. 2003. Biomineralization and evolutionary history. Rev Mineral Geochem 54: 329-356.

Koshizuka Y, Ikegawa S, Sano M, Nakamura K, Nakamura Y. 2001. Isolation of novel mouse genes associated with ectopic ossification by differential display method using $\mathrm{ttw}$, a mouse model for ectopic ossification. Cytogenet Cell Genet 94: 163-168.

Kovacs CS. 2003. Skeletal physiology: Fetus and neonate. In Primer on the metabolic bone diseases and disorders of mineral metabolism. American Society for Bone and Mineral Research, Washington, DC.

Li J, Manickam G, Ray S, Oh CD, Yasuda H, Moffatt P, Murshed M. 2016. Smpd3 expression in both chondrocytes and osteoblasts is required for normal endochondral bone development. Mol Cell Biol 36: 2282-2299.
Luo G, D'Souza R, Hogue D, Karsenty G. 1995. The matrix Gla protein gene is a marker of the chondrogenesis cell lineage during mouse development. J Bone Miner Res 10: 325-334.

Luo G, Ducy P, McKee MD, Pinero GJ, Loyer E, Behringer RR, Karsenty G. 1997. Spontaneous calcification of arteries and cartilage in mice lacking matrix GLA protein. Nature 386: 78-81.

Macrae VE, Davey MG, McTeir L, Narisawa S, Yadav MC, Millan JL, Farquharson C. 2010. Inhibition of PHOSPHO1 activity results in impaired skeletal mineralization during limb development of the chick. Bone 46: 11461155.

Mahamid J, Sharir A, Addadi L, Weiner S. 2008. Amorphous calcium phosphate is a major component of the forming fin bones of zebrafish: Indications for an amorphous precursor phase. Proc Natl Acad Sci 105: 12748-12753.

Mahamid J, Aichmayer B, Shimoni E, Ziblat R, Li C, Siegel S, Paris O, Fratzl P, Weiner S, Addadi L. 2010. Mapping amorphous calcium phosphate transformation into crystalline mineral from the cell to the bone in zebrafish fin rays. Proc Natl Acad Sci 107: 6316-6321.

Martin A, Liu S, David V, Li H, Karydis A, Feng JQ, Quarles LD. 2011. Bone proteins PHEX and DMP1 regulate fibroblastic growth factor Fgf23 expression in osteocytes through a common pathway involving FGF receptor (FGFR) signaling. FASEB J 25: 2551-2562.

Marulanda J, Eimar H, McKee MD, Berkvens M, Nelea V, Roman H, Borrás T, Tamimi F, Ferron M, Murshed M. 2017. Matrix Gla protein deficiency impairs nasal septum growth, causing midface hypoplasia. J Biol Chem 292: 11400-11412.

Masuyama R, Nakaya Y, Tanaka S, Tsurukami H, Nakamura T, Watanabe S, Yoshizawa T, Kato S, Suzuki K. 2001. Dietary phosphorus restriction reverses the impaired bone mineralization in vitamin $\mathrm{D}$ receptor knockout mice. Endocrinology 142: 494-497.

Mebarek S, Abousalham A, Magne D, Do le D, Bandorowicz-Pikula J, Pikula S, Buchet R. 2013. Phospholipases of mineralization competent cells and matrix vesicles: Roles in physiological and pathological mineralizations. Int $J$ Mol Sci 14: 5036-5129.

Mergenhagen SE, Martin GR, Rizzo AA, Wright DN, Scott DB. 1960. Calcification in vivo of implanted collagen. Biochim Biophys Acta 43: 563-565.

Mornet E. 2000. Hypophosphatasia: The mutations in the tissue-nonspecific alkaline phosphatase gene. $\mathrm{Hum} \mathrm{Mu-}$ tat 15: 309-315.

Munroe PB, Olgunturk RO, Fryns JP, Van Maldergem L, Ziereisen F, Yuksel B, Gardiner RM, Chung E. 1999. Mutations in the gene encoding the human matrix Gla protein cause Keutel syndrome. Nat Genet 21: 142-144.

Murshed M, Schinke T, McKee MD, Karsenty G. 2004. Extracellular matrix mineralization is regulated locally; different roles of two gla-containing proteins. J Cell Biol 165: 625-630.

Murshed M, Harmey D, Millan JL, McKee MD, Karsenty G. 2005. Unique coexpression in osteoblasts of broadly expressed genes accounts for the spatial restriction of ECM mineralization to bone. Genes Dev 19: 1093-1104. 
Obeid LM, Linardic CM, Karolak LA, Hannun YA. 1993. Programmed cell death induced by ceramide. Science 259: $1769-1771$

Panda DK, Miao D, Tremblay ML, Sirois J, Farookhi R, Hendy GN, Goltzman D. 2001. Targeted ablation of the 25-hydroxyvitamin D 1 $\alpha$-hydroxylase enzyme: Evidence for skeletal, reproductive, and immune dysfunction. Proc Natl Acad Sci 98: 7498-7503.

Pasteris JD, Wopenka B, Freeman JJ, Rogers K, ValsamiJones E, van der Houwen JA, Silva MJ. 2004. Lack of $\mathrm{OH}$ in nanocrystalline apatite as a function of degree of atomic order: Implications for bone and biomaterials. Biomaterials 25: 229-238.

Price PA, Williamson MK. 1985. Primary structure of bovine matrix Gla protein, a new vitamin K-dependent bone protein. J Biol Chem 260: 14971-14975.

Price PA, Toroian D, Lim JE. 2009. Mineralization by inhibitor exclusion: The calcification of collagen with fetuin. $J$ Biol Chem 284: 17092-17101.

Rey C, Miquel JL, Facchini L, Legrand AP, Glimcher MJ. 1995. Hydroxyl groups in bone mineral. Bone 16: 583586.

Rey C, Combes C, Drouet C, Glimcher MJ. 2009. Bone mineral: Update on chemical composition and structure. Osteoporos Int 20: 1013-1021.

Scheele CW. 1931. The collected papers of Carl Wilhelm Scheele (translated by Leonard Dobbin). G. Bell \& Sons, London.

Sheldon H, Robinson RA. 1957. Electron microscope studies of crystal-collagen relationships in bone. IV: The occurrence of crystals within collagen fibrils. J Biophys Biochem Cytol 3: 1011-1016.

Shoulders MD, Raines RT. 2009. Collagen structure and stability. Annu Rev Biochem 78: 929-958.

Stoffel W, Jenke B, Block B, Zumbansen M, Koebke J. 2005. Neutral sphingomyelinase 2 (smpd3) in the control of postnatal growth and development. Proc Natl Acad Sci 102: 4554-4559.

Stoffel W, Jenke B, Holz B, Binczek E, Günter RH, Knifka J, Koebke J, Niehoff A. 2007. Neutral sphingomyelinase (SMPD3) deficiency causes a novel form of chondrodysplasia and dwarfism that is rescued by Col2A1-driven smpd3 transgene expression. Am J Pathol 171: 153-161.

Suda T, Takahashi N, Abe E. 1992. Role of vitamin D in bone resorption. J Cell Biochem 49: 53-58.

Taillandier A, Cozien E, Muller F, Merrien Y, Bonnin E, Fribourg C, Simon-Bouy B, Serre JL, Bieth E, Brenner $\mathrm{R}$, et al. 2000. Fifteen new mutations (-195C >T, L-12X,
298-2A $>$ G, T117N, A159T, R229S, 997+2T>A, E274X, A331T, H364R, D389G, 1256delC, R433H, N461I, $\mathrm{C} 472 \mathrm{~S})$ in the tissue-nonspecific alkaline phosphatase (TNSALP) gene in patients with hypophosphatasia. Hum Mutat 15: 293.

Taillandier A, Lia-Baldini AS, Mouchard M, Robin B, Muller F, Simon-Bouy B, Serre JL, Bera-Louville A, Bonduelle M, Eckhardt J, et al. 2001. Twelve novel mutations in the tissue-nonspecific alkaline phosphatase gene (ALPL) in patients with various forms of hypophosphatasia. Hum Mutat 18: 83-84.

Terkeltaub RA. 2001. Inorganic pyrophosphate generation and disposition in pathophysiology. Am J Physiol Cell Physiol 281: C1-C11.

Toroian D, Lim JE, Price PA. 2007. The size exclusion characteristics of type I collagen: Implications for the role of noncollagenous bone constituents in mineralization. $J$ Biol Chem 282: 22437-22447.

Tu Q, Pi M, Karsenty G, Simpson L, Liu S, Quarles LD. 2003. Rescue of the skeletal phenotype in CasR-deficient mice by transfer onto the $\mathrm{Gcm} 2$ null background. J Clin Invest 111: 1029-1037.

Wagner DO, Aspenberg P. 2011. Where did bone come from? Acta Orthop 82: 393-398.

Wu LN, Genge BR, Kang MW, Arsenault AL, Wuthier RE. 2002. Changes in phospholipid extractability and composition accompany mineralization of chicken growth plate cartilage matrix vesicles. J Biol Chem 277: 5126-5133.

Xia W, Meng X, Jiang Y, Li M, Xing X, Pang L, Wang O, Pei Y, Yu LY, Sun Y, et al. 2007. Three novel mutations of the PHEX gene in three Chinese families with X-linked dominant hypophosphatemic rickets. Calcif Tissue Int 81: 415-420.

Yadav MC, Lemire I, Leonard P, Boileau G, Blond L, Beliveau M, Cory E, Sah RL, Whyte MP, Crine P, et al. 2011a. Dose response of bone-targeted enzyme replacement for murine hypophosphatasia. Bone 49: 250-256.

Yadav MC, Simão AM, Narisawa S, Huesa C, McKee MD, Farquharson C, Millán JL. 2011b. Loss of skeletal mineralization by the simultaneous ablation of PHOSPHO1 and alkaline phosphatase function: A unified model of the mechanisms of initiation of skeletal calcification. $J$ Bone Miner Res 26: 286-297.

Yang X, Matsuda K, Bialek P, Jacquot S, Masuoka HC, Schinke T, Li L, Brancorsini S, Sassone-Corsi P, Townes TM, et al. 2004. ATF4 is a substrate of RSK2 and an essential regulator of osteoblast biology; implication for Coffin-Lowry syndrome. Cell 117: 387-398. 


\section{$\$ \mathrm{CSH} \&$ Cold Spring Harbor

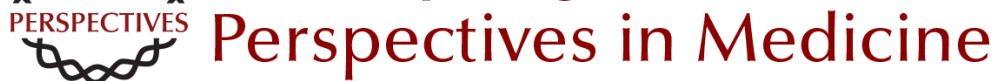

\section{Mechanism of Bone Mineralization}

Monzur Murshed

Cold Spring Harb Perspect Med 2018; doi: 10.1101/cshperspect.a031229 originally published online April 2, 2018

\section{Subject Collection Bone: A Regulator of Physiology}

\section{Mechanism of Bone Mineralization} Monzur Murshed

Neural Regulation of Bone and Bone Marrow Maria Maryanovich, Shoichiro Takeishi and Paul S. Frenette

Regulation of Bone Remodeling by Parathyroid Hormone Marc N. Wein and Henry M. Kronenberg

The Bone Marrow Microenvironment in Health and Myeloid Malignancy

Marta Galán-Díez, Álvaro Cuesta-Domínguez and Stavroula Kousteni

The Biology of Bone Metastasis

Mark Esposito, Theresa Guise and Yibin Kang

\section{Bone Remodeling and the Microbiome} Roberto Pacifici

\section{Osteoimmunology}

Kazuo Okamoto and Hiroshi Takayanagi

Multiple Myeloma and Bone: The Fatal Interaction Silvia Marino and G. David Roodman

Biology of Bone: The Vasculature of the Skeletal System

Emma C. Watson and Ralf H. Adams

Regulation of Energy Metabolism by

Bone-Derived Hormones

Paula Mera, Mathieu Ferron and Ioanna Mosialou

\section{Biology of Fibroblast Growth Factor 23: From \\ Physiology to Pathology \\ Marie Courbebaisse and Beate Lanske}

Regulation of Bone Metabolism by Sex Steroids Sundeep Khosla and David G. Monroe

For additional articles in this collection, see http://perspectivesinmedicine.cshlp.org/cgi/collection/ 